\title{
FURTHER DEVELOPMENTS ON BIODIESEL PRODUCTION AND APPLICATIONS IN BRAZIL
}

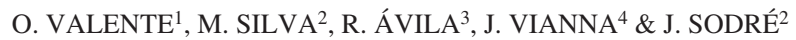 \\ ${ }^{1}$ Federal Center of Technological Education of Minas Gerais, Brazil. \\ ${ }^{2}$ Pontifical Catholic University of Minas Gerais, Brazil. \\ ${ }^{3}$ FIAT Automobiles S.A., Brazil. \\ ${ }^{4}$ University of Brasilia, Brazil.
}

\begin{abstract}
Environmental concerns have motivated many countries to search for solutions to reduce fossil fuel consumption. In the last few years, biodiesel has attracted attention as a possible sustainable and renewable energy source to substitute diesel oil. Biodiesel can be produced from different oleaginous plants, but there are worries about food competition and forests and biodiversity-rich areas devastation to produce biodiesel. Even considering biodiesel as a promising solution, its production impacts must be carefully evaluated. This work examines the Brazilian prospects for biodiesel production and use as an engine fuel for automotive propulsion and power generation. The potential for biodiesel production of many native and adapted oleaginous plants in Brazilian territory is discussed. Experimental results of hydrocarbons, carbon monoxide, and carbon dioxide emissions from a diesel power generator fuelled by blends of diesel oil and castor oil or soybean biodiesel are also presented.

Keywords: biodiesel, carbon emissions, castor oil, renewable energy, sustainable development, soybean.
\end{abstract}

\section{INTRODUCTION}

Diesel fuelled vehicles are mainly used for load and public transportation in Brazil. Over 2 million trucks circulate along $1.6 \times 10^{6} \mathrm{~km}$ roads, transporting $61 \%$ of the total cargo. Meanwhile, 95,000 buses are used for public transportation in urban areas. The annual amount of diesel oil consumed by the transportation system is about $42,100 \mathrm{~m}^{3}$, of which $38,600 \mathrm{~m}^{3}$ are refined in the country. The remaining 3,500 $\mathrm{m}^{3}$ of diesel oil are imported. Diesel oil imports reduction, social inclusion and environmental issues are the main justification to support discussion about introduction of biodiesel as a Brazilian alternative energy source.

Brazil's climate diversity and multiple soil conditions allow for a variety of vegetation to grow in its territory. A study performed by Minas Gerais Technological Center Foundation [1] revealed nine oleaginous plants as economically efficient sources for biodiesel production. The investigation has not included peanut, cotton, canola (colza), and soybean, which have recently been widely used as raw material for biodiesel production. The oil produced by each oleaginous plant shows different physical-chemical characteristics. Some oil properties, such as viscosity and density, influence in engine fuel consumption and exhaust emissions. Following Brazilian ethanol experience, the use of biodiesel fuel as a renewable energy source is expected to become economically feasible and ecologically correct.

\section{BRAZILIAN POTENTIAL FOR BIODIESEL PRODUCTION}

\subsection{Main oleaginous plants and geographic distribution}

With diversified climate, regular rains, abundant solar energy and almost $13 \%$ of all fresh water available in the planet, according to data supplied by the Brazilian Ministry of Agriculture, Brazil has $388 \times 10^{6}$ ha of fertile and high productivity soil. About $90 \times 10^{6}$ ha of Brazilian territory have 
not yet been explored. Besides, Brazil is one of the few countries where it is possible to plant in mild and tropical areas. Brazilian agriculture can supply up to two annual grain harvests.

According to Brazilian Ministry of Agriculture, from 1990 to 2003 grain production in Brazil increased $131 \%$ [2]. During this period, the cultivated area increased only $16.1 \%$. Thirteen different harvests were the main reason for this growth. The efficiency of agricultural production grew from 1.5 to 2.8 tons/ha. Research efforts on environmentally friend technology for farming and cattleraising have been responsible for the development of 529 new adapted crops to each climate and soil in the main production regions. The procedures adopted include application of only the necessary nutrients, rehabilitation of degraded land and the use of rotational grazing.

With more than 90 million hectares of fertile lands available, Brazil can increase at least three times its current grain production, from 123.2 million to 367.2 million tons. This amount can even increase if it is considered that about one-third of 220 million hectares presently used to raise cattle can be turned into crop fields. The country is likely to reach 140 million hectares addressed to agriculture from expansion of its cultivated borders in the Center-Western and North-Eastern regions. The adopted environmental policy is planned to keep the Brazilian rain forest untouched. Ethanol fuel production from sugarcane has proved to be a successful experience, showing the possibility of producing biofuels without competing with food production.

Biodiesel can be produced from vegetable oils or animal fat. The strategy adopted by the Brazilian Agro-Cattle Research Company (EMBRAPA) considers some potential plants for biodiesel production: tucumã (Astrocaryum aculeatum), macaúba (Acrocomia intumescens), pequi (Caryocar brasiliense), physic nut (Jatropha curcas), baru (Hibiscus tiliaceus), murumuru (Astrocaryum murumuru), buriti (Trithrinax schizophylla), inajá (Maximiliana maripa), andiroba (Carapa guianensis), tucum (Astrocaryum vulgare), babaçu (Orbignya phalerata), tungue (Aleurites moluccana), colza (Brassica napus), turnip (Brassica rapa), crambe, sesamum, palm (Elaeis guineensis), indaiá (Attalea oleifera), castor plant (Ricinus communis) and flax (Linum usitatissimum). Some of these vegetables, native and well-adapted to several Brazilian micro-climates, can produce $>1$ ton/ha (Table 1 ).

\subsection{Estimative of planting area}

Due to its social and economic role, castor plant is one of the most promising oleaginous for biodiesel production. The Brazilian state of Bahia is responsible for $90 \%$ of the national production. The small farmers have a tradition to share the castor plant cultivation area with black beans, corn, and others. In the North-Eastern region, there are 406 counties adequate for castor plant cultivation, making a total planting area of 45 million ha. The period from 1984 to 1985 produced the largest harvest in the last 40 years, corresponding to 300,000 ton, but occupied $<1 \%$ of the available area [3]. The productivity was $726 \mathrm{~kg} / \mathrm{ha}$, being the highest recorded until 2004/2005, when $963 \mathrm{~kg} / \mathrm{ha}$ was reached. From the 1984/1986 peak, the harvest showed a systematic fall until making a recovery in the 2001/2002 period, as shown in Fig. 1.

In 2005, though the biodiesel production units in the region were not yet fully operational, castor plant production in the North-Eastern region was over 202,000 ton (Fig. 1), corresponding to 209,800 ha planting area. From this total, Bahia produced 170,000 ton, with a productivity of $1,000 \mathrm{~kg} / \mathrm{ha}$. Though biodiesel production in the Center and in the Southern region is $8 \%$ lower than that of the North-Eastern region, the productivity of that region is as high as 1,400 kg/ha. EMBRAPA estimates that, with adequate techniques, the productivity can significantly increase, giving castor plant the potential to be part of a vigorous social inclusion program on the basis of biodiesel production. 
Table 1: Brazilian oleaginous plants location and estimated oil production [1].

\begin{tabular}{llc}
\hline Plants & \multicolumn{1}{c}{ Location } & Production (ton/ha) \\
\hline Palm tree & Amazonas, Pará & 4.37 \\
Macaúba & Minas Gerais, Goiás & 2.63 \\
Physic nut & Bahia, Minas Gerais & 3.99 \\
Indaiá & Bahia, Minas Gerais & 0.94 \\
Castor oil & North-Eastern region & 0.73 \\
Sunflower & Southern region, Mato Grosso, Goiás & 0.31 \\
Soybean & Southern region, Mato Grosso, Goiás & 0.3 \\
\hline
\end{tabular}

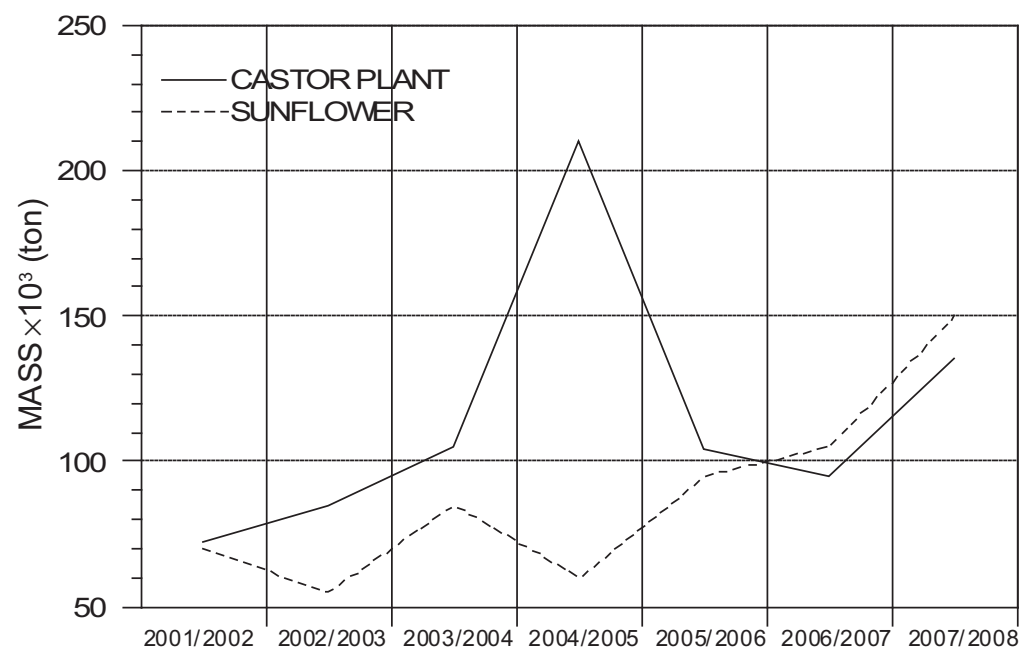

Figure 1: Castor plant and sunflower production in Brazil [3].

Sunflower is another oleaginous plant that is getting importance for biodiesel production. Since 1997, when 9,600 ha were planted in the Center-Western region, sunflower production has systematically increased (Fig. 1). In the North-Eastern region, sunflower planting was initiated in 2006, in Rio Grande do Norte state, on an area of 800 ha. There is an indication that the productivity of that region can reach $1,100 \mathrm{~kg} / \mathrm{ha}$. The planting area is expected to expand up to 7,000 ha.

One ton of sunflower can produce $400 \mathrm{~kg}$ of oil, $350 \mathrm{~kg}$ of non-toxic cake plus $30 \%$ proteins and $250 \mathrm{~kg}$ of shell. It also has a potential to produce $20 \mathrm{~L}$ of ethanol. These characteristics associated with the vegetative cycle of 100 days and the good adaptability of sunflower to succeed other plant cultures makes it a good alternative to attend the demand for oil production in the North-Eastern region. A sustainable development project can overcame the lack of experience with this oleaginous in the region, considering economic, environmental and social issues.

Physic nut is also an oleaginous of good potential for biodiesel production in the North-Eastern region. It shows a good record for both plant raising and biodiesel production, having favorable physical-chemical characteristics (Table 2). Tiwari et al. [4] characterized the whole industrial process of biodiesel production from physic nut. The results confirm that the physical-chemical characteristics of physic nut biodiesel attend DIN and ASTM standards for use as a pure fuel (B100) 
Table 2: Physical-chemical properties of physic nut (Jatropha Curcas) and diesel oil [4].

\begin{tabular}{lcccc}
\hline Parameter & Vegetable oil & Biodiesel & Diesel oil & Standard \\
\hline Density at $15^{\circ} \mathrm{C}\left(\mathrm{kg} / \mathrm{m}^{3}\right)$ & 940 & 880 & 850 & $860-900 \mathrm{DIN}$ \\
Viscosity at $15^{\circ} \mathrm{C}\left(\mathrm{mm}^{2} / \mathrm{s}\right)$ & 24.5 & 4.8 & 2.6 & $1.9-6.0$ ASTM \\
Flash point $\left({ }^{\circ} \mathrm{C}\right)$ & 225 & 135 & 68 & $>130$ DIN \\
Cloud point $\left({ }^{\circ} \mathrm{C}\right)$ & 4 & 2 & -20 & - \\
Carbon residue $(\%)$ & 1.0 & 0.20 & 0.17 & $<0.30$ \\
Heating value $(\mathrm{MJ} / \mathrm{kg})$ & 38.65 & 39.23 & 42.0 & - \\
\hline
\end{tabular}

or blended with diesel oil. While the studies conducted by EMBRAPA to define the most adequate species for biodiesel production in Brazil are not yet finished, there is an indication that physic nut is adequate for production in the North-Eastern region. The productivity of physic nut is between 2,000 and $3,000 \mathrm{~kg} / \mathrm{ha}$, with an oil content of $30 \%$. It also shows as an advantage the characteristic of being a perennial plant, with a life cycle over 40 years.

Biodiesel production in the Brazilian North-Eastern region and in the semi-arid region can reach a volume superior to 1.5 million $\mathrm{m}^{3}$. Over a half of this capacity is already in operation. The necessary area to attend the raw material demand, for safe and permanent offer, will depend on the type of oleaginous plant and its productivity. This is connected to two fundamental aspects: adaptation of the oleaginous plant to the soil type and development of technologies to improve the planting system.

Biodiversity protection and guaranteed food supply are two important components to be considered for agro-energy production. Biodiesel certification must also follow ethic agreements. To adequate the oleaginous species to the biophysical context of the region, it is necessary to map it for correct administration of the available area, including optimization of spatial distribution of the production units and environmental protection. The estimated area for biodiesel production from several oleaginous plants range from 415,000 to 2,838,000 ha. Even considering that oleaginous planting will not demand a continuous area, the environmental impacts must strongly be considered, together with the risk of food supply compromise.

\subsection{Soybean and castor oil biodiesel}

Two oleaginous plants are mainly discussed for biodiesel production in Brazil: soybean and castor oil. The choice for soybean has been justified by a well-established productivity chain, being able to promptly attend the growing demand for biodiesel. Castor oil is justified by its potential to become an instrument for public policy of social inclusion without affecting food production. Those plants have distinct production systems and social and environment impacts. However, they can complement each other for biodiesel production when all aspects are considered: economical, social, geographic, environmental and technical.

\subsubsection{Soybean industry}

The soybean industry became consolidated in Brazil from significant changes performed in the agricultural sector. The soybean industry is originated from the first stages of industrialization of Brazil's agricultural production, but became a structured sector at the same pace as its cultivation activities became integrated with other economy sectors. Even though in 1973 circumstantial aspects 
influenced the expansion of soybean plantations, the type of production and its technological and commercial aspects allowed its continuous expansion.

It should be stressed the role of the Brazilian government on the expansion of soybean production. First, there were policies to stimulate agricultural modernization; second, there were incentives to increase crop value, such as taxation of grain exports, in order to stimulate the export of sub-products. According to Roessing and Stolf [5], in 1990, the participation of soybean products on Brazilian exports $(32.0 \%)$ exceeded the total amount of all other basic products $(28.4 \%)$.

From the beginning of soybean cultivation on commercial scale to the present Brazil reached a strong participation in the international market. Brazilian soybean production was initially concentrated in the traditional region comprised by the states of São Paulo, Paraná, Santa Catarina and Rio Grande do Sul. In 1995, for the first time, the output of these traditional regions fell below the level of $70 \%$ of the amount harvested in the country. In 2006, this value had fallen to only $28.6 \%$. At present, the output from the state of Mato Grosso alone, located in Brazilian Center-Western region, is almost as large as the output from the entire Brazilian Southern region [6].

Another significant element on the expansion of soybean plantation and on the sectors related to it is the way the farmers behave with respect to their activities. Soybean producers are dynamic players in the expansion process, reacting promptly to public policies and to international markets. Soybean producers modernized the business and adapted to the demands for internal food production and raw materials. For the international markets the soybean farmers supply primary products as commodities. In both contexts, success was based on the technological standards adopted by the farmers. According to Wehrmann [7], soybean farmers have a standard behavior that results in small differences on the way this activity is conducted.

The control of the production processes can be added to technological and management efficiency, based on transformation of past experiences into prosperous future [6], and the tendency to migration. The historical facts of soybean cultivation in Brazil include two remarkable internal migrations. The first migration started in Rio Grande do Sul state and ended in Paraná state, both located in the Brazilian Southern region. The second migration was characterized by many soybean farmers moving to semiarid areas in the Center-Western region. An emerging third migration movement is now taking soybean farmers towards the Amazon region [7, 8].

This internal migration, although organized and encouraged by the Government, with the aim to explore abandoned areas of the national territory, was also a search for opportunities to expand cultivated areas. The expansion of soybean plantations in Brazil was remarkable: in 1970, 1.319 $\times 10^{6}$ ha were occupied; by 2008 , that figure increased to $21.3 \times 10^{6}$ ha. The average output also increased in the same period, from 1,211 to $2,816 \mathrm{~kg} / \mathrm{ha}$.

Installations for soybean crushing were also deployed rapidly in Brazil. According to the Brazilian Association of Vegetable Oil Industries (ABIOVE) [8], in 1996, the installed crushing capacity was of 111,475 tons/day, and, in 2008, this capacity was reported as 155,449 tons/day (Table 3 ).

It should be mentioned that, in 1996, this industrial complex was already consolidated and, in the following period, some industrial units moved to regions closer to grain production, while less efficient units were closed (Table 3). The migration of crushing facilities to the Center and the Southern region of the country follows the movement of grain production. Considering Brazil's continental extension, biodiesel production will strongly benefit from regional diffusion, balanced with diesel consumption throughout the country. The decentralization noticed in Table 3 is possibly a favorable starting point for biodiesel production, since it offers an opportunity to regional fuel supply, avoiding long-distance transportation.

Large corporate groups are responsible for $50 \%$ of the crushing capacity. In the 2008/2009 harvest, only $46 \%$ of the installed crushing capacity was used. The increase in oil production came in 
Table 3: Soybean crushing capacity in Brazilian states in 1996 and in 2008 (tons/day) [8].

\begin{tabular}{lcr}
\hline State & 1996 & 2008 \\
\hline Paraná & 35,370 & 35,150 \\
Rio Grande do Sul & 29,000 & 25,800 \\
Mato Grosso & 8,330 & 24,800 \\
São Paulo & 11,110 & 17,780 \\
Goiás & 7,450 & 19,250 \\
Mato Grosso do Sul & 6,780 & 9,575 \\
Minas Gerais & 4,300 & 6,600 \\
Bahia & 2,600 & 5,530 \\
Santa Catarina & 5,075 & 4,034 \\
Amazonas & - & 2,000 \\
Pernambuco & - & 400 \\
Piauí & 260 & 2,530 \\
Maranhão & - & 2,000 \\
Brazil (total) & 111,475 & 155,449 \\
\hline
\end{tabular}

response to external market demands for meal and cakes, since oil is not the most important export item of soybean products. In the 2008/2009 harvest, 30 million tons of grains were crushed, generating 6.187 million tons of oil [6]. This means that the sector has an additional production capacity of 5 million tons of oil, demonstrating the potential for biofuel production with no need to invest in the entire biodiesel production chain.

\subsubsection{Economic and social aspects of soybean biodiesel production}

Soybean biodiesel production can be based on the strategic use of part of the nominal crushing capacity installed in the country, currently used at a rate of only 55\%. To complete the biodiesel production process it would be necessary to bring the transesterification units close to the crushing units. This would mean that the current distribution of the control over the agro-industrial sector would not change, as 50\% of the sector is controlled by only four economic groups. Pasquis [9] mentions that restrictions to inclusion of new companies are leading to control of the crushing segment by large international groups. In the case of biodiesel production, this situation will not change, given that the oil production segment provides the best opportunities for future improvement of the soybean industry competitiveness.

It is clear that soybean biodiesel has a strong potential for economic sustainability, since it can open new markets for traditional agriculture. However, this potential does not minimize the environmental impacts caused by large-scale soybean production, especially if there is an increase in cultivated area. Even if the current cultivated area is not expanded, soybean biodiesel production is not environmentally sustainable, since it will bring only a small reduction in engine emissions and does not affect the carbon balance. Carbon sequestration by oilseed plantations is one of the important strategies to be considered in all aspects related to stabilization of carbon dioxide $\left(\mathrm{CO}_{2}\right)$ concentration in the atmosphere. Even though, carbon emissions due to the use of fertilizers and due to the refining process may counterbalance carbon sequestration by soybean plants. Soybean plantation causes mid term land degradation, thus requiring rotational grazing. 
Regarding social aspects, soybean biodiesel is not sustainable either, since it will not change the current state of work force employment. Soybean production is highly mechanized, concentrating incomes, and is socially exclusionary. Thus, the option for soybean biodiesel is not the most appropriate when considering job creation, especially when compared with other oilseeds, such as castor bean. A modern mill for soybean processing, with a crushing capacity of 2.5 tons/day, can employ 40 people; the increase in $2.5 \times 10^{6}$ tons/year would create 11,000 new jobs. On the other hand, with respect to biodiesel production from castor bean, the federal government has the goals of settling 153,000 families and generating $1.53 \times 10^{6}$ jobs in the entire production chain until the year 2010 . These goals result from an estimated production capacity of $1.5 \times 10^{6}$ tons/year of castor bean biodiesel, allowing for a mixture of up to $5 \%$ of castor bean biodiesel in diesel oil. Therefore, taking castor bean as a reference, soybean biodiesel has a weak social sustainability.

\subsubsection{Energy balance and carbon sequestration in the production chain of soybean biodiesel} The energy balance is the most important indicator to determine the viability of a biofuel. There are only a few studies of biodiesel energy balance for Brazilian conditions. Preliminary estimates of energy production/consumption ratio for soybean biodiesel have been presented in 1982 as 1.42 [7]. That is, for each energy unit introduced in the entire biodiesel production chain, 1.42 units of energy are obtained. These studies estimate an energy demand of $30 \mathrm{MJ}$ to produce $1 \mathrm{~L}$ of soybean biodiesel, without considering agricultural and industrial by-products. Recent studies conducted by Mendonça [10], using the methodology of Life Cycle Evaluation, considered all phases of the soybean production chain, including soil preparation, planting, crop treatments, harvest, storage and residues. The energy balance also considered the energy flux of the entire industrial process. The results showed that, for each unit of energy introduced in the system, 1.65 units of renewable energy are obtained. This is not a high figure when compared to palm biodiesel, which has an energy performance up to 5.6.

Also using the Life Cycle Evaluation methodology, Mendonça [10] computed equivalent $\mathrm{CO}_{2}$ emissions throughout the entire soybean biodiesel production chain, considering all variables involved in the agricultural and industrial process: agricultural products, residues, oil extraction and transesterification, glycerin use and transport. The results indicate that, for pure biodiesel (B100), the entire system absorbs $12 \%$ more equivalent $\mathrm{CO}_{2}$ than the amount emitted. The relation between carbon input and output is 1.2. These results show that the introduction of soybean biodiesel in the energy grid, although displaying a positive balance, has only a modest energy and environmental performance, considering thermodynamic aspects and the potential to mitigate the greenhouse effect.

\subsubsection{Social aspects of castor oil biodiesel production}

The Brazilian semi-arid region, comprising part of the North-Eastern and the Center-Western regions, is characterized by low water availability. Even though, it is a region with a vast diversity of vegetation, oil and climate, and with a traditional small farming culture. The region shows one of the lowest human development indexes in the country, with cheap land prices and high demographic density. Production of biodiesel raw materials is an opportunity to improve the social and economic standard of the region.

Many oleaginous plants have adequate conditions for their development in the Brazilian semiarid region. Vegetable species such as castor plant, physic nut, cotton and sunflower, among others, are appropriate for growth in lands of naturally difficult use or degraded by conventional agriculture. Some of those species are already part of the region's small farmers quotidian, who are also used to cultivate their own food supply, such as black beans and corn. Thus, it is expected that biodiesel production will be an important mean to use degraded lands, to improve traditional production systems, and to promote social inclusion through economic incomes and job offer increase in the Brazilian semi-arid region. 
Even considering those possibilities, production of oleaginous plants in adequate quantities for biodiesel production requires large planting areas, high productivity volume and regular offer. It should be well-planned to avoid reduction of food supply and negative environmental impacts. Conservation of biodiversity in the semi-arid region is a permanent challenge for consolidation of the Brazilian National Program for Biodiesel Production and Use (PNPB), in 2004.

Small farming is responsible for 7 out of 10 employees in the Brazilian agriculture sector, and participates with $40 \%$ of the total agriculture production in the country [4]. In the North-Eastern region, this economic activity employs 6.2 million people, distributed in 2.7 million establishments. This group of people, with their habits for diversified agriculture and a historical connection to the land, can be organized to find in the agro-energy sector a way to increase incomes and improve the social and economic conditions. This can contribute to reduce regional differences and to stimulate the fixation of small farming. Nonetheless, the participation of small farmers to produce biodiesel raw material is still negligible [10]. Many North-Eastern states are traditional producers of agriculture products for the food industry, such as black beans and corn.

Another social category that must be considered in the biodiesel production chain is the landless people. The landless people camped in the North-Eastern region totalize 144,000 families distributed in 582 counties. This socially excluded group has been a permanent source of economic, environmental and social conflicts. The agro-energy business must be seen as an opportunity to formulate a policy to include the landless people in the biodiesel production chain. This aspect must be emphasized by its economic impact and by ethics recommendation.

\subsubsection{Economic aspects of castor oil biodiesel production}

The numerous applications of castor oil bring it a high commercial value in the international market. In 2008, soybean oil was quoted at US $\$ 1,400$ per ton, while castor oil was quoted at US\$3,200 per ton. In the beginning of 2009 , the castor oil price was still high, preventing its presence in biodiesel auctions promoted by the Brazilian National Oil and Natural Gas Agency (ANP). Thus, only a considerable increase of castor oil offer can change the situation to promote a safe delivery to the biodiesel industry. Despite, the difficulties for castor oil biodiesel production in the North-Eastern region and the physical-chemical limitations, such as high viscosity, there are at least six reasons that justify this culture:

1. Small farmers are familiarized with castor plant cultivation.

2. Castor plant is highly resistant to dry soil and weather conditions.

3. It shows a potential for recovery of degraded lands that are inappropriate for other cultures.

4. Castor plant can be cultivated together with food plants, such as black beans and corn.

5. There is a high potential for increasing productivity.

6. Flexible application of crude oil assures market demand and positive net incomes.

The following sections show a brief review of the use of biodiesel as engine fuel and experimental results obtained from a diesel power generator fuelled by castor oil and soybean biodiesel. The results give complementary information to compare the use of soybean and castor oil biodiesel with diesel oil regarding engine performance, exhaust emissions and carbon balance.

\section{LITERATURE REVIEW ON ENGINE USE OF BIODIESEL}

McCormick et al. [11] studied the effects of 14 oils from different origins on emissions from heavy duty vehicles. The authors verified that the biodiesel molecular structure has a substantial impact on exhaust emissions. Particulate matter (PM) and oxides of nitrogen emissions increased with increasing 
fuel density. Cetane number did not influence particulate matter emissions, but higher cetane number decreased oxides of nitrogen emissions $\left(\mathrm{NO}_{\mathrm{X}}\right)$.

Haas et al. [12] demonstrated that the use of vegetable or animal fat oils, modified by the transesterification process, reduce engine carbon and PM emissions, while oxides of nitrogen emissions are increased.

Çetinkaya and Karaosmanoğlu [13] obtained results from a diesel power generator that demonstrate soot reduction by use of a blend of $20 \%$ used cooking oil biodiesel in diesel oil. The use of biodiesel increased the specific fuel consumption in comparison with diesel oil operation.

Szybist et al. [14] concluded that retarded injection timing improves engine performance when biodiesel is used as fuel. Tsolakis [15] demonstrated that the utilization of exhaust gas recirculation reduces PM and oxides of nitrogen emissions.

Leung et al. [16] carried out experiments in a single-cylinder engine with modified injection timing, orifice diameter and injection pressure. The objective was to verify the influence of those parameters on $\mathrm{HC}, \mathrm{NO}_{\mathrm{X}}$, and $\mathrm{PM}$ emissions. The authors noticed that increasing orifice diameter, retarding the injection timing by four crank angle degrees, and increasing the injection pressure approximated the fuel burning process to top dead center, thus increasing combustion efficiency. It was concluded that, with adequate settings, fuelling the engine with pure biodiesel can decrease hydrocarbons (HCs), oxides of nitrogen and PM emissions in comparison with diesel oil.

Kegl [17] performed experiments in a heavy duty diesel engine to adequate it for colza biodiesel fuelling. The author attempted to optimize the injection setting for minimum exhaust emissions and fuel consumption. Pure biodiesel (B100) and diesel oil were tested. The results showed that fuelling the unmodified engine with B100 caused a decrease in performance. Modifications in the injection system settings significantly reduced $\mathrm{HCs}$, oxides of nitrogen and soot emissions. A slight reduction of carbon monoxide $(\mathrm{CO})$ emission was also observed when pure biodiesel was used, while engine output power and exhaust gas temperature was unaltered. The engine thermal efficiency was slightly increased with the use of pure biodiesel, but specific fuel consumption was also increased by about $10 \%$.

Several aspects of biodiesel production and use in Brazil were presented by Valente et al. [18] including results on engine exhaust emissions using soybean and castor oil biodiesel blends.

\section{EXPERIMENTS IN A BIODIESEL-FUELLED ENGINE}

Blends of petroleum-based diesel oil and two types of biodiesel, obtained from castor oil and soybean, were laboratory tested (Table 4). A four-cylinder, 3.8-L, compression-ignition engine connected to a power generator of $50 \mathrm{~kW}$ maximum power was used to measure $\mathrm{HC}, \mathrm{CO}$, and $\mathrm{CO}_{2}$ exhaust emissions. A bank of electric resistances was used to apply load to the power generator, allowing for minimum load steps of $2.5 \mathrm{~kW}$. A power quality analyzer was used to record the electric current frequency, intensity and tension. A flame ionization detector analyzer was used to measure total exhaust $\mathrm{HCs}$ concentration. $\mathrm{CO}$ and $\mathrm{CO}_{2}$ emissions were both measured by a non-dispersive infra-red analyzer (NDIR). The ambient conditions were monitored through a thermal-hygrometer and a barometer.

The engine had a warm-up period of about $15 \mathrm{~min}$ and the gas analyzers were turned on about $1 \mathrm{~h}$ prior to the tests. After setting the load, a 2-min interval was allowed for stabilization of the engine before proceeding with the instrument readings. The gas sample flowing into the analyzers was collected direct from the engine exhaust, close to the exhaust port. The ambient air temperature was kept at $28 \pm 2^{\circ} \mathrm{C}$. The exhaust components were measured at the nominal loads of $0,10,20,30$, and $40 \mathrm{~kW}$. The results shown in the following section represent the average of three tests performed for each fuel blend. 
Table 4: Description of fuel blends used in the tests.

\begin{tabular}{ll}
\hline Blend & \multicolumn{1}{c}{ Composition } \\
\hline B0 & Petroleum-based diesel oil \\
B5M & Blend of 5\% castor oil biodiesel and 95\% diesel oil \\
B5S & Blend of 5\% soybean biodiesel and 95\% diesel oil \\
B20M & Blend of 20\% castor oil biodiesel and 80\% diesel oil \\
B20S & Blend of 20\% soybean biodiesel and 80\% diesel oil \\
B35M & Blend of 35\% castor oil biodiesel and 65\% diesel oil \\
B35S & Blend of 35\% soybean biodiesel and 65\% diesel oil \\
B50S & Blend of 50\% soybean biodiesel and 50\% diesel oil \\
B85S & Blend of 85\% soybean biodiesel and 15\% diesel oil \\
\hline
\end{tabular}

\section{RESULTS AND DISCUSSION}

Figures 2-10 show the variation of exhaust $\mathrm{HC}, \mathrm{CO}$ and $\mathrm{CO}_{2}$ emissions for varying biodiesel concentration and engine load. The presence of exhaust HCs is a result of incomplete combustion occurring in the chamber (Figs 2 and 3). HC concentration is higher for very high or very low load. Under very low loads, the lean air/fuel mixture causes slow combustion reaction and, eventually, flame extinction. With very high loads, the enriched air/fuel mixture can provoke flame quenching due to temperature drop in the chamber caused by excessive fuel evaporation.

In Figs 2 and 3, the increase of HC emissions with the use of the biodiesel fuel blends is accounted to the biodiesel physical-chemical characteristics. Both castor oil and soybean biodiesel have higher density than diesel oil (Fig. 4). As the fuel injection system displaces constant volumes, the same volumetric amount injected corresponds to higher biodiesel mass amount in comparison with diesel oil, enriching the air/fuel mixture (Figs 5 and 6). As mentioned before, the engine injection system was kept with its original settings, which are optimized for diesel fuel operation. This result indicates the need of modifications in the injection system to optimize it for biodiesel operation, as observed by Szybist et al. [14], Leung et al. [16], and Kegl [17]. The effects of fuel density are more clearly noticed for castor oil biodiesel blends (Fig. 2) than for soybean biodiesel blends (Fig. 3).

Figures 7 and 8 show a linear decrease of $\mathrm{CO}$ concentration with increasing load. That is an indication of better fuel atomization being attained under higher load, probably caused by the higher combustion chamber temperatures that follow higher peak pressures. Increased biodiesel concentration in the fuel blend provokes an increase in $\mathrm{CO}$ emissions. That is because of air/fuel mixture enrichment (Figs 5 and 6) due to higher biodiesel mass being injected by the fuel pump, which volume displacement is optimized to diesel oil operation. As previously mentioned, once the density of biodiesel is higher than that of diesel oil (Fig. 4), for a same displaced volume, higher biodiesel mass is injected in comparison with diesel oil. For a given load and biodiesel concentration, soybean biodiesel showed higher $\mathrm{CO}$ concentration than castor oil biodiesel (Figs 7 and 8).

In Figs 9 and 10, an increase in $\mathrm{CO}_{2}$ emissions with increasing load is observed. $\mathrm{CO}_{2}$ formation increases as the air/fuel mixture strength is closer to stoichiometric (see Figs 5 and 6). For a given load applied to the engine, $\mathrm{CO}_{2}$ concentration is basically the same for any biodiesel concentration in the fuel blend. The concentration of $\mathrm{CO}_{2}$ also showed to be insensitive to biodiesel type, showing practically the same results for both, castor oil and soybean biodiesel.

To project the effects of these results on the Brazilian transportation fleet, one should consider an estimated fleet of over 1.2 million light, medium and heavy duty vehicles [19], with an annual 


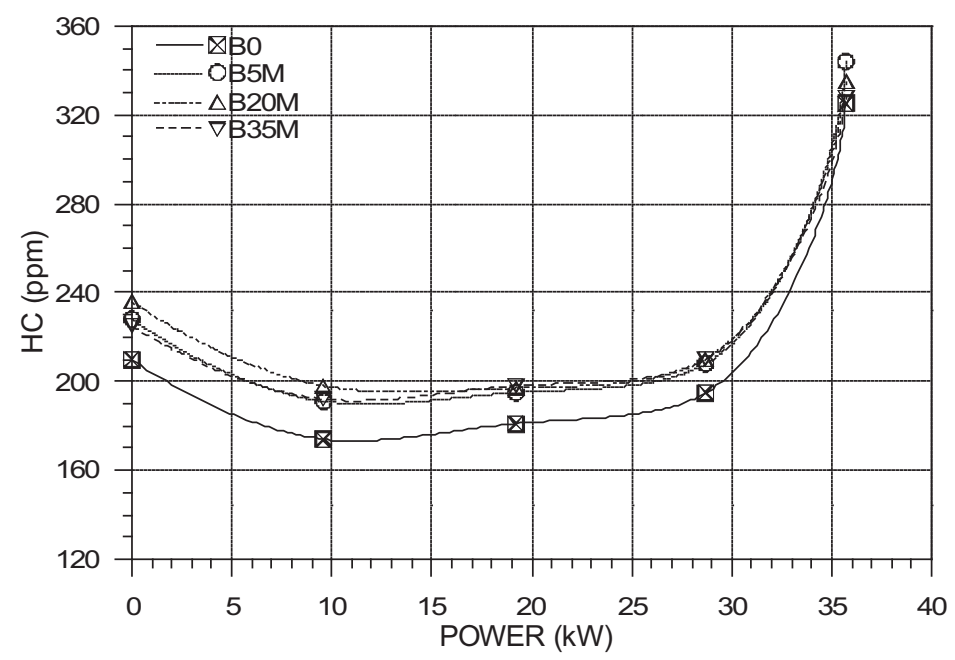

Figure 2: Variation of exhaust hydrocarbon concentration with engine load for castor oil biodiesel blends.

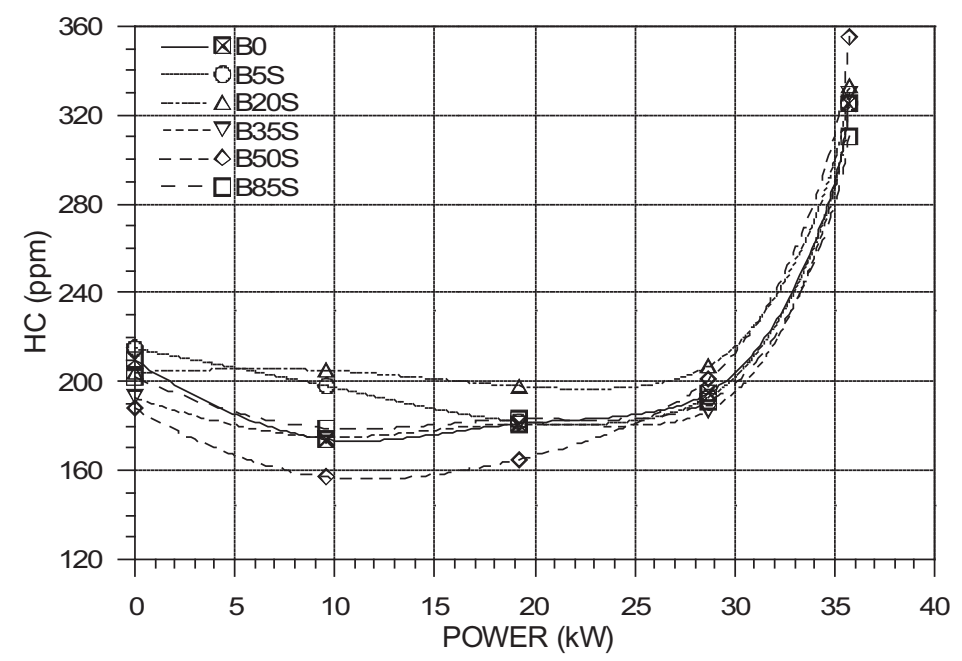

Figure 3: Variation of exhaust hydrocarbon concentration with engine load for soybean biodiesel blends.

consumption of diesel oil of around $42 \times 10^{6} \mathrm{~m}^{3}$ [20]. Each vehicle can be considered to produce average specific $\mathrm{HC}, \mathrm{CO}$ and $\mathrm{CO}_{2}$ emissions of $2.0,1.5$ and $650 \mathrm{~g} / \mathrm{kW} \cdot \mathrm{h}$, respectively. Considering also that each vehicle operates $2,100 \mathrm{~h}$ a year transporting $15,000 \mathrm{~kg}$ fuelled by diesel oil, 1.26 million tons of $\mathrm{HC}, 0.95$ million tons of $\mathrm{CO}$ and 410 million tons of $\mathrm{CO}_{2}$ are produced. If $20 \%$ of diesel oil is replaced by soybean biodiesel, $\mathrm{HC}$ and $\mathrm{CO}$ emissions would be increased by 0.1 and 0.2 million tons a year, respectively, while $\mathrm{CO}_{2}$ emissions would be unaffected. 


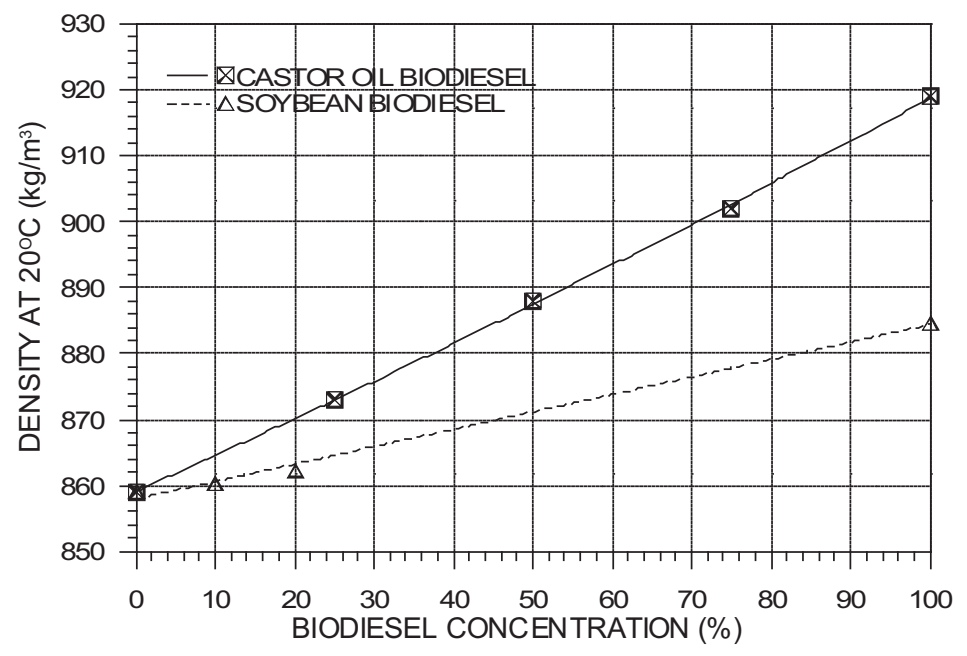

Figure 4: Variation of fuel density with biodiesel concentration.

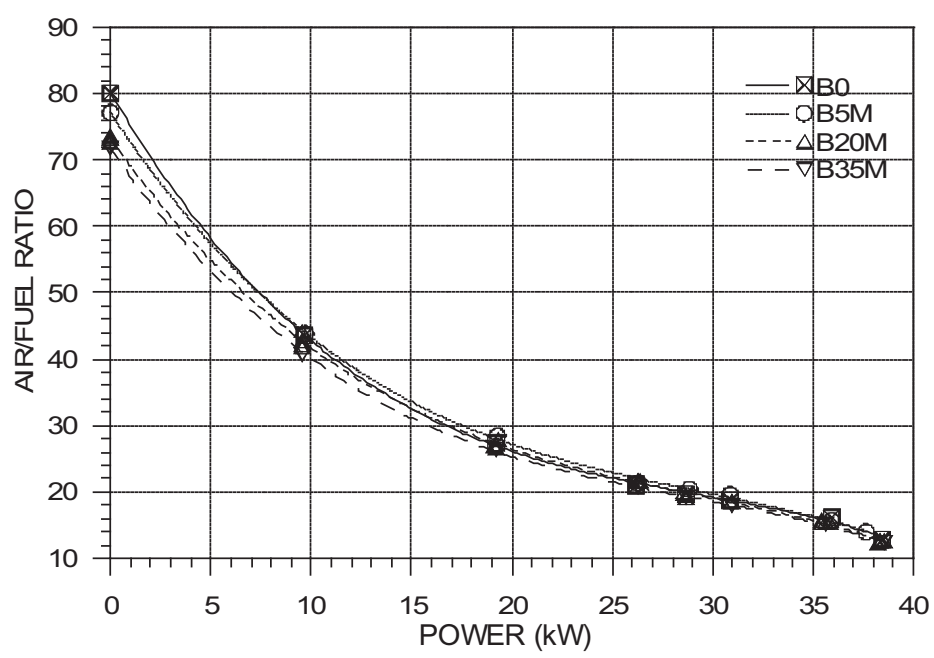

Figure 5: Variation of mixture strength with engine load for castor oil biodiesel blends.

According to the Brazilian National Agency for Petroleum, Natural Gas and Biofuels, ANP [20], each $1 \%$, v/v, addition of biodiesel to diesel oil reduces $\mathrm{CO}_{2}$ emission by $3 \%$, considering the whole biodiesel production chain. This means a reduction of 1.2 million ton of $\mathrm{CO}_{2}$ emission released to the environment. Di Carlo et al. [21] used the methodology of Life Cycle Assessment to study the technical viability of the use of biodiesel as a potential substitute to diesel oil. The authors evaluated land preparation, the use of fertilizers and the exhaust emissions produced in a travel of $1,000 \mathrm{~km}$. It was concluded that the life cycle analysis of canola biodiesel from well to tank is favorable in comparison with diesel oil, causing a reduction of $78 \%$ of global warming potential if all biodiesel 


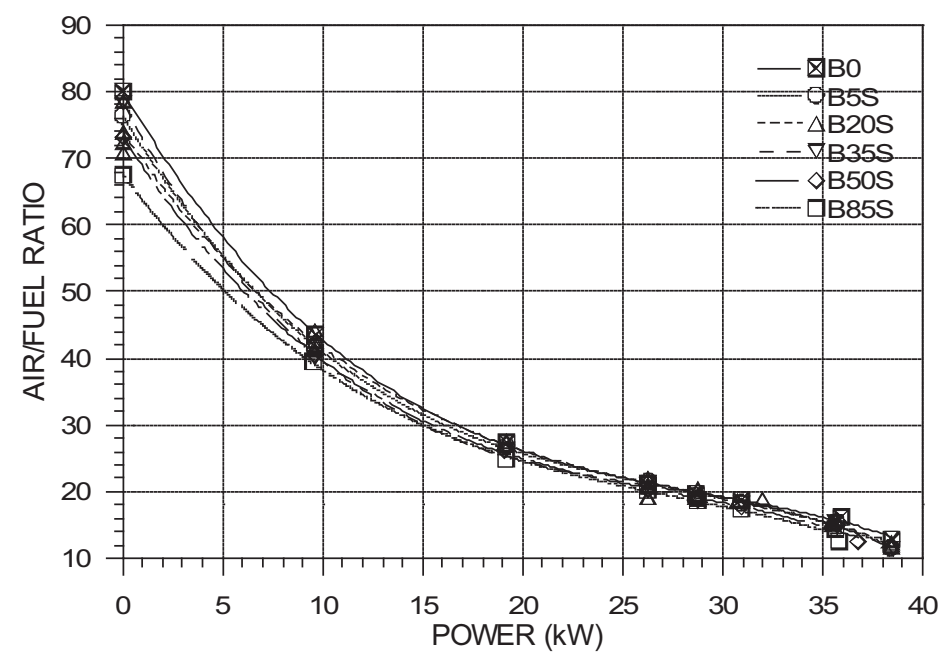

Figure 6: Variation of mixture strength with engine load for soybean biodiesel blends.

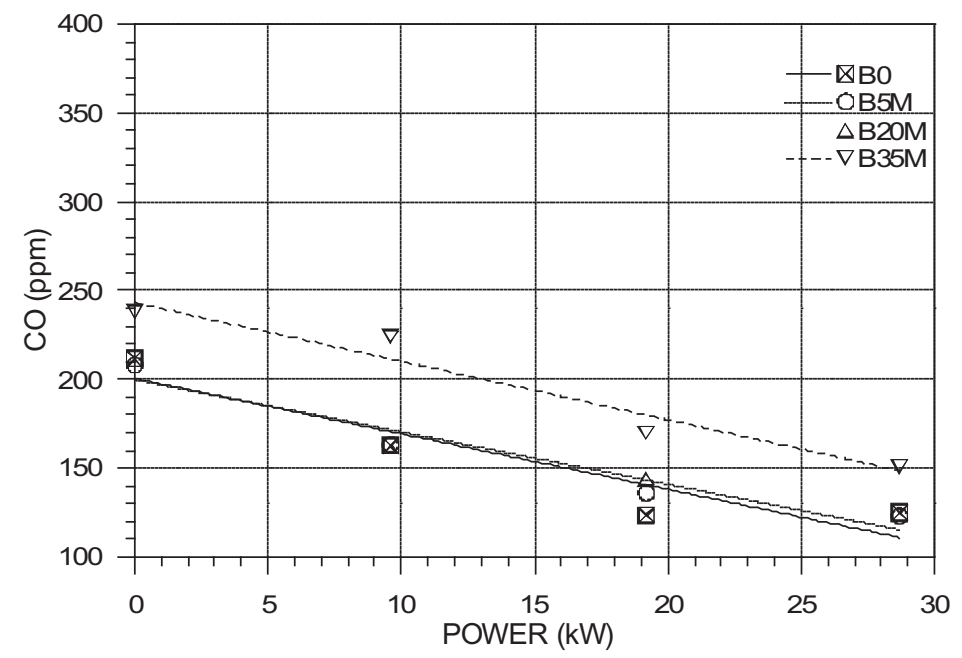

Figure 7: Variation of exhaust carbon monoxide concentration with engine load for castor oil biodiesel blends.

by-products are utilized. Sheehan et al. [22] used the Life Cycle Inventory methodology to evaluate the environmental impact of the use of soybean biodiesel in comparison with diesel oil from well to tank. This study concluded that the use of biodiesel to fuel buses reduces $\mathrm{CO}_{2}$ emission by $78 \%$, showing a similar figure as [21]. Although the initial costs of biodiesel production are higher than those of diesel oil, the use of recycling can turn the use of biodiesel more favorable both environmentally and financially. 


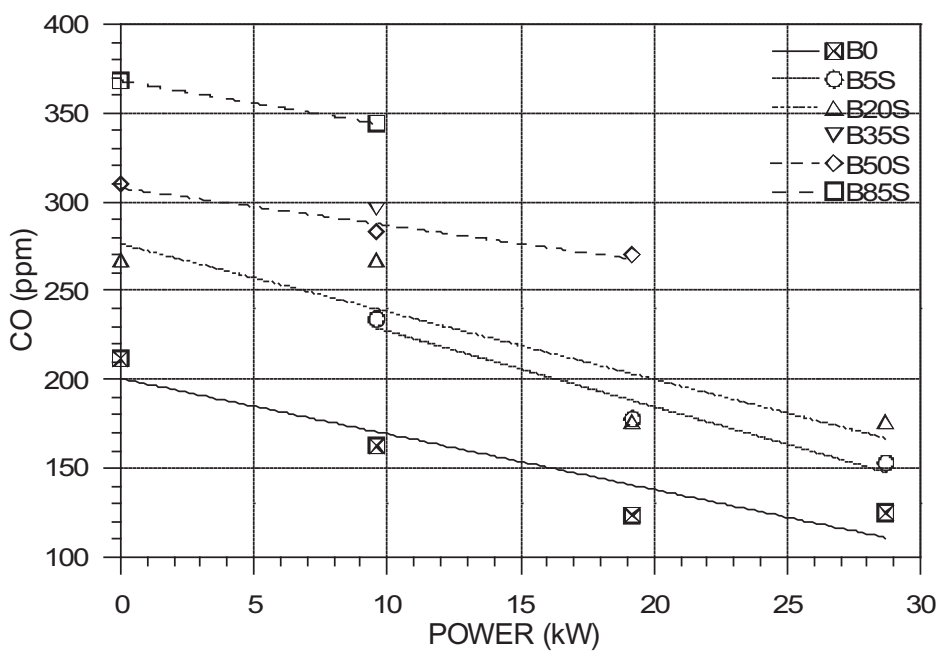

Figure 8: Variation of exhaust carbon monoxide concentration with engine load for soybean biodiesel blends.

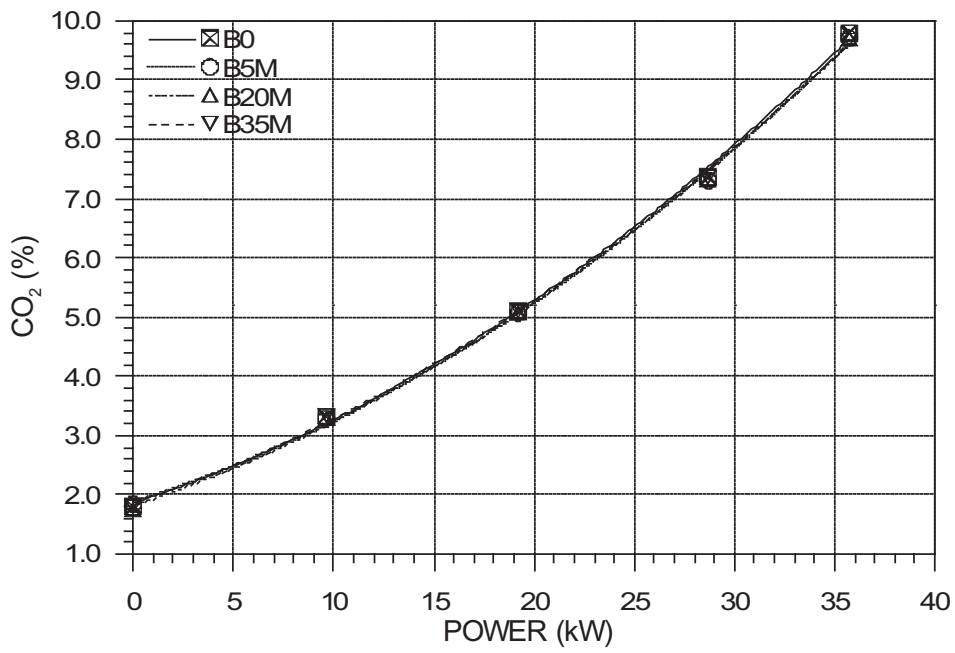

Figure 9: Variation of exhaust carbon dioxide concentration with engine load for castor oil biodiesel blends.

From these studies [20-22] and from the observations made by [10], and also considering the results from Figs 9 and 10, it can be affirmed that the use of biodiesel causes no impact on $\mathrm{CO}_{2}$ emission in comparison with diesel oil, if one considers engine exhaust concentration only. However, if it is considered the overall biodiesel production chain, the substitution of diesel oil by biodiesel can produce significant reductions on $\mathrm{CO}_{2}$ emission and, consequently, on global warming potential. In this case, the reduction of $\mathrm{CO}_{2}$ emission can be as high as $78 \%$. 


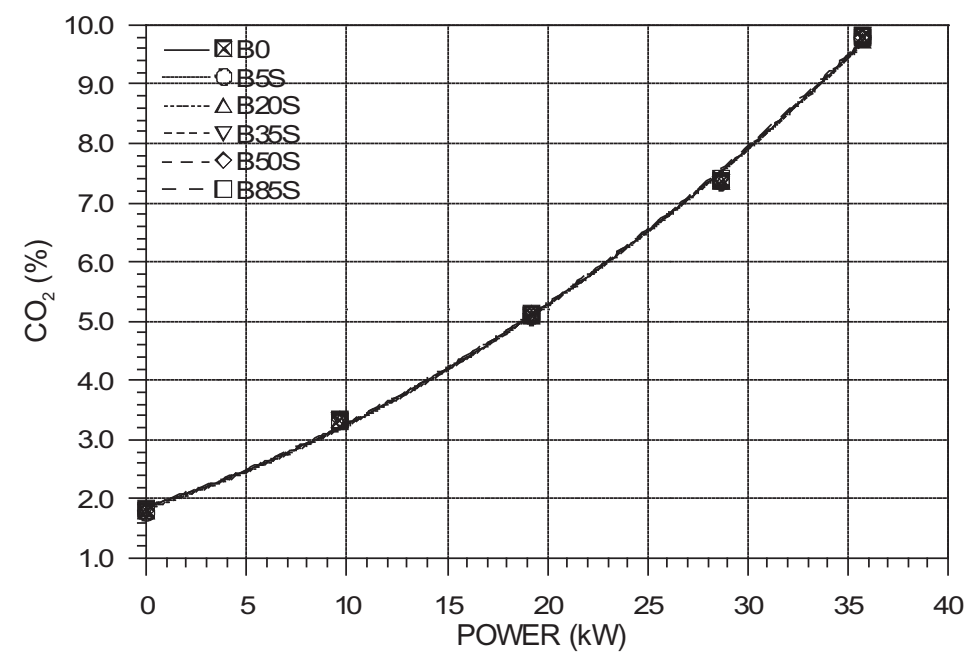

Figure 10: Variation of exhaust carbon dioxide concentration with engine load for soybean biodiesel blends.

\section{CONCLUSIONS}

- Brazil presents appropriate conditions for oleaginous plant production and biodiesel distribution, but faces the task of choosing the most economically attractive from more than ten oleaginous types available.

- Soybean biodiesel is economically viable, though socially exclusive, environmentally harmful and unsustainable.

- Experiments in a power generator showed that exhaust HC emissions increase with increasing castor oil or soybean biodiesel concentration in diesel oil, with no engine modification.

- Increasing castor oil or soybean biodiesel concentration in diesel oil increases CO emission.

- Castor oil showed lower CO emission levels than soybean biodiesel for varying engine load.

- $\mathrm{CO}_{2}$ emission level was not altered by biodiesel type or concentration in diesel oil throughout the load range studied.

- Due to increasing fuel density, air/fuel mixture is enriched with increasing biodiesel concentration for all loads.

- The use of biodiesel requires modification in power generator injection systems to reduce engine exhaust pollutants and $\mathrm{CO}_{2}$ emissions.

- The sole use of biodiesel as engine fuel does not assure significant environmental advantages; major impacts will depend on the whole production chain.

\section{ACKNOWLEDGMENTS}

The authors thank CNPq and Varginha City Council for the financial support to this project.

\section{REFERENCES}

[1] CETEC-MG, Production of Liquid Fuels from Vegetable Oils, Minas Gerais Technological Center Foundation Report: Belo Horizonte, MG, Brazil, 1983.

[2] Geomundo, www.geomundo.com.br/geografia-30105.htm, 2010.

[3] CONAB, www.conab.gov.br. 
[4] Tiwari, A.K., Kumar, A. \& Raheman, H., Biodiesel production from jatropha oil (Jatropha curcas) with high free fatty acids: an optimized process. Biomass and Bioenergy, 31(8), pp. 569-575, 2007. doi:10.1016/j.biombioe.2007.03.003

[5] Roessing, A.C. \& Stolf, L.C., Soybean: Economical Aspects and Contribution to Brazilian Economy Growth, EMBRAPA: Brazil, 2000.

[6] Garcez, C.A.G. \& Vianna, J.N.S., Brazilian biodiesel policy: social and environmental considerations of sustainability. Energy, 34(5), pp. 645-654, 2009. doi:10.1016/j.energy.2008.11.005

[7] Wehrmann, www.wehrmann.com.br, 2009.

[8] ABIOVE, www.abiove.com.br, 2009.

[9] Pasquis, R., Preliminary Study on the Evolution of Agro Reform Projects in Legal Amazon, CIRAD-UnB-CenDoTec Report: Paris, France, 2004.

[10] Mendonça, R.M.L., Evaluation of Carbon Life Cycle from Soybean Biodiesel Burn, University of Brasília: Brasília, DF, Brazil, 2007.

[11] McCormick, R.L., Graboski, M.S., Alleman, T.L. \& Herring, A.M., Impact of biodiesel source material and chemical structure on emissions of criteria pollutants from a heavy-duty engine. Environmental Science and Technology, 35(9), pp. 1742-1747, 2001. doi:10.1021/es001636t

[12] Haas, M.J., Scott, K.M., Alleman, T.L. \& McCormick, R.L., Biodiesel fuel prepared from soybean soapstock: a high quality renewable fuel produced from a waste feedstock. Energy \& Fuels, 15(5), pp. 1207-1212, 2001. doi:10.1021/ef010051x

[13] Çetinkaya, M. \& Karaosmanoğlu, F., A new application area for used cooking oil originated biodiesel: generators. Energy \& Fuels, 19(2), pp. 645-652, 2005. doi:10.1021/ef049890k

[14] Szybist, J.P., Boehmana, A.L., Taylorb, J.D. \& McCormick, R.L., Evaluation of formulation strategies to eliminate the biodiesel $\mathrm{NO}_{\mathrm{X}}$ effect. Fuel Processing Technology, 86(10), pp. 1109-1126, 2005. doi:10.1016/j.fuproc.2004.11.006

[15] Tsolakis, A., Effects on particle size distribution from the diesel engine operating on RMEbiodiesel with EGR. Energy \& Fuels, 20(4), pp. 1418-1424, 2006. doi:10.1021/ef050385c

[16] Leung, D., Lou, Y. \& Chan, T.L., Optimization of exhaust emissions of a diesel engine fuelled with biodiesel. Energy \& Fuels, 20(3), pp. 1015-1023, 2006. doi:10.1021/ef050383s

[17] Kegl, B., Experimental investigation of optimal timing of the diesel engine injection pump using biodiesel. Energy \& Fuels, 20(4), pp. 1460-1470, 2006.

[18] Valente, O., Silva, M., Ávila, R., Vianna, J. \& Sodré, J., Sustainable development aspects of biodiesel production and application in Brazil, Sustainable Development and Planning IV, vol. 2, eds. C.A. Brebbia, M. Neophytou, E. Beriatos, I. Ioannou \& A.G. Kungolos, WIT Press: Southampton, Boston, pp. 733-742, 2009.

[19] COPPEAD, www.coppead.com.br, 2008.

[20] ANP, www.anp.gov.br, 2009.

[21] Di Carlo, S., Serra, R. \& Foglia, G., Application of LCA methodologies in the automobile sector: two Fiat Auto experiences, SAE Technical Paper 971203, 1997.

[22] Sheehan, J., Camobreco, V., Duffield, J., Graboski, M. \& Shapouri, H., An overview of biodiesel and petroleum diesel life cycles. Report of National Renewable Energy Laboratory (NREL) and US-Department of Energy (DOE). Task No. BF886002, 1998. 